\title{
PAULO FREIRE UM CLÁSSICO DA EDUCAÇÃO: CONTRIBUIÇÕES EPISTÊMICAS, POLÍTICAS E PEDAGÓGICAS
}

\author{
Telmo Marcon ${ }^{1}$ \\ Ivan Penteado Dourado ${ }^{2}$
}

\begin{abstract}
Resumo
O artigo de natureza bibliográfica tem por objetivo fundamentar a tese que Paulo Freire é um clássico da educação e tem muito a contribuir para pensar os desafios emergentes na atualidade, tanto do contexto global, quanto da sociedade brasileira. Para fundamentar a tese que Freire é um clássico, buscam-se as contribuições de Ítalo Calvino, quando apresenta vários argumentos do porque ler um clássico, bem como as contribuições de Raymond Williams para embasar a ideia de que um clássico mantém a sua vitalidade na medida em que consegue problematizar e responder aos desafios emergentes em diferentes contextos. Esses dois autores ajudam a fundamentar a tese que Paulo Freire é um clássico da educação, porque respondeu questões de seu tempo, mas as suas ideias continuam provocando reflexões relativas a problemas epistêmicos, políticos e educacionais emergentes no tempo presente.
\end{abstract}

Palavras-chave: Educação; Democracia; Clássico; Paulo Freire; Política Educacional

\section{PAULO FREIRE A CLASSIC OF EDUCATION: EPISTEMIC, POLITICAL AND PEDAGOGICAL CONTRIBUTIONS}

\begin{abstract}
The bibliographical article aims to support the thesis that Paulo Freire is a classic of education and has much to contribute to think about the emerging challenges in the present time of both the global context and the Brazilian society. The thesis that Freire is a classic is based on the

\footnotetext{
${ }^{1}$ Doutor em História Social pela PUC/SP, pós-doutorado em Educação intercultural pela UFSC. Professor e pesquisador no PPGEDU da Universidade de Passo Fundo. Endereço: Rua Coronel Gabriel Bastos, 13, apto 401, bairro Vergueiro, 99020-100 - Passo Fundo/RS. E-mail: telmomarcon@ gmail.com.

${ }^{2}$ Doutor em Educação pela Universidade de Passo Fundo (UPF). Professor e pesquisador no Instituto de Filosofia e Ciências Humanas da UPF. Endereço: BR Km 292, Av. Brasil Leste, 285 - 99052-900 - Bairro São José, Passo Fundo - RS. E-mail: ivan.dourado@acad.pucrs.br.
}

Revista Reflexão e Ação, Santa Cruz do Sul, v. 25, n. 2, p. 84-100, Maio./Ago. 2017.

http://online.unisc.br/seer/index.php/reflex/index
\end{abstract}


contributions of Italo Calvino when he presents several arguments to justify why to read a classic, as well as the contributions of Raymond Williams to support the idea that a classic maintains its vitality as long as it can problematize and respond to challenges arising in different contexts. These two authors help to support the proposition that Paulo Freire is a classic of education because he answered questions of his time, whose ideas continue to provoke reflections on epistemic, political and educational emerging problems in the present time.

Keywords: Education; Democracy; Classic. Paulo Freire; Educationalpolitics

\section{PAULO FREIRE UN CLÁSICO DE LA EDUCACIÓN: CONTRIBUCIONES EPISTÉMICAS, POLÍTICAS Y PEDAGÓGICAS}

\section{Resumen}

El artículo de naturaleza bibliográfica tiene por objetivo fundamentar la tesis que Paulo Freire es un clásico de la educación y tiene mucho que contribuir a pensar los desafíos emergentes en la actualidad tanto del contexto global, como de la sociedad brasileña. Para fundamentar la tesis que Freire es un clásico se buscan las contribuciones de Ítalo Calvino cuando presenta varios argumentos del por qué leer un clásico, así como las contribuciones de Raymond Williams para basar la idea de que un clásico mantiene su vitalidad en la medida en que es capaz de problematizar y responder a los desafíos emergentes en diferentes contextos. Estos dos autores ayudan a fundamentar la tesis que Paulo Freire es un clásico de la educación porque respondió cuestiones de su tiempo, pero sus ideas continúan provocando reflexiones relativas a problemas epistémicos, políticos y educacionales emergentes en el tiempo presente.

Palabras-clave: Educación; Democracia; Clásico; Paulo Freire; Política Educacional

\section{CONSIDERAÇÕES INTRODUTÓRIAS}

Que razões podem, ainda, justificar pesquisas sobre Paulo Freire? Pesquisas desenvolvidas no mundo todo sobre esse autor resultaram em milhares de teses, dissertações, monografias, livros, capítulos de livros e artigos em periódicos. Uma breve pesquisa no 
Google, site de busca, com base no discriminador Paulo Freire, realizada em julho de 2016, apontou 44 milhões de resultados. Centros de estudos em torno do autor multiplicam-se em inúmeros países. Outra breve pesquisa no Google com o discriminador "Institutos Paulo Freire no Mundo" resultou em 389.000. Em uma pesquisa recente na plataforma do Google acadêmico, aparecem mais de 35.000 referências ao autor, incluindo artigos, teses e dissertações. Entre as obras de Freire, A Pedagogia do Oprimido (1981) tem, com certeza, um dos lugares mais privilegiados no mundo. Em 2016, esse livro aparece entre os 100 mais citados no mundo, segundo a Open Syllabus ${ }^{3}$ (2016), nas ementas em programas de estudos em universidades dos Estados Unidos, Reino Unido, Austrália e Nova Zelândia. Sobre essa extraordinária produção, Carlos Novoa (1981, p. 9) faz o seguinte comentário:

\begin{abstract}
Há uma saturação de material sobre Freire, e que nos induz a pensar que se trata de um fenômeno cujas causas transcendem a própria influência intelectual exercida por Freire sobre toda uma geração de educadores, sociólogos, filósofos e intelectuais em geral (o que poderia ser um modismo), projetando-se até uma causa eficiente que explicaria esse interesse e preocupação atuais.
\end{abstract}

Diante desses dados, o que ainda pode ser pesquisado sobre Freire e como ele pode contribuir no contexto atual? Ainda existem potencialidades de pesquisas de natureza bibliográfica sobre o autor? Evidente que sempre existem possibilidades teóricas para reconstruir um autor do porte de Freire na perspectiva da pesquisa bibliográfica. No entanto, pretendemos defender, aqui, as potencialidades que Freire ainda tem, priorizando outro caminho que não é, também, o de simplesmente legitimar pesquisas empíricas. Considerando a sua condição de autor clássico no campo da educação, pretendemos fundamentar a tese de que ele ainda tem potencialidades para responder questões emergentes na contemporaneidade, algumas das quais ele sequer imaginou, ou seja, a sua potencialidade está na capacidade de ajudar a pensar o emergente, conforme pontua Raymond Williams (2011). Essa possibilidade pressupõe, evidentemente, um domínio epistêmico e pedagógico profundo e ampliado do autor. Dessa forma, pensamos ser possível revitalizar as ideias de um pensador que é fecundo, mas que necessita ser provocado e oxigenado. As interrogações emergentes carregam uma “força messiânica", conforme aponta Walter Benjamin (1994, p. 223), quando afirma: "a cada

\footnotetext{
${ }^{3}$ Uma pesquisa recente realizada pela Opensyllabus coletou mais de um milhão de ementas e programas de estudos em universidades de países como: Estados Unidos, Reino Unido, Austrália e Nova Zelândia para identificar os livros mais solicitados em suas ementas. O resultado é que A Pedagogia do Oprimido, lançado em 1968, consta como a $99^{\circ}$ obra mais citada no ranking geral. <Disponível em: http://opensyllabusproject.org/. Acesso em 30 de Agosto de 2016>.
}

Revista Reflexão e Ação, Santa Cruz do Sul, v. 25, n. 2, p. 84-100, Maio./Ago. 2017. http://online.unisc.br/seer/index.php/reflex/index 
geração, foi-nos concedida uma frágil força messiânica para a qual o passado dirige um apelo. Esse apelo não pode ser rejeitado impunemente..."

A obra freireana é muito complexa, ao contrário do que se pode pensar. Considerando que o autor usa uma linguagem que é, aparentemente, simples, pode dar a impressão que o seu entendimento também é de fácil compreensão. Esse é, certamente, um equívoco. A densidade perpassa a sua obra, os autores e as diferentes tradições com os quais dialoga, bem como a sua proposta pedagógica e educativa pensada como ação política que visa conscientizar os oprimidos da sua condição para que lutem pela emancipação. Essas breves considerações são suficientes para evidenciar a complexidade do autor e as questões formuladas por ele.

Para fundamentar a tese que pretendemos defender, tomamos a liberdade de invocar os poucos autores que fazem uma reflexão específica e consistente em relação ao papel dos clássicos. Um deles trata-se de Ítalo Calvino que, na obra Por que ler os clássicos (1993), dedica um capítulo para refletir sobre o que é uma obra clássica. Não pretendemos analisar uma obra específica de Freire, mas estender a noção de Calvino para o conjunto das reflexões de seu autor, ou seja, o sentido de clássico, aqui, não se limita a uma obra, mas ao conjunto da obra desse autor. Num segundo momento, pretendemos fundamentar o conceito de emergente a partir das reflexões de Raymond Williams (2011), tendo presente, em nosso entender, que um clássico é capaz de jogar luz sobre as interrogações emergentes. Finalmente, pretendemos pensar nas potencialidades da obra freireana para refletir sobre os grandes desafios sociais e educativos contemporâneos, especialmente os educacionais.

\section{PAULO FREIRE: UM CLÁSSICO DA EDUCAÇÃO}

Que elementos permitem identificar e definir um clássico? Paradoxalmente, fala-se muito de clássicos em diferentes áreas do conhecimento. Segundo Alexander (1999), em algumas áreas do conhecimento, existe resistência em utilizar o conceito de clássico há pouca reflexão teórica a respeito, tanto de autores quanto de obras individuais. Nas áreas humanas e sociais, esse conceito é aceito, mesmo que as suas configurações nem sempre sejam as mesmas. Entre as poucas produções destaca-se a de Ítalo Calvino. Nessa obra, Calvino (1993, p. 11) sistematiza, em aproximadamente oito páginas, quatorze definições de clássico, das quais pode-se destacar, no contexto da presente reflexão, algumas delas. 
Clássico é um livro que nunca terminou de dizer aquilo que tinha para dizer. [...] os clássicos são aqueles livros que chegam até nós trazendo consigo as marcas das leituras que precederam a nossa e atrás de si os traços que deixaram na cultura ou nas culturas que atravessaram (ou mais simplesmente na linguagem ou nos costumes).

Calvino sugere ainda que sejam sempre indicadas leituras de clássicos porque eles surpreendem.

Um clássico é uma obra que provoca incessantemente uma nuvem de discursos sobre si, mas continuamente as repele para longe. [...] Os clássicos são livros que, quanto mais pensamos conhecer por ouvir dizer, quando são lidos de fato mais se revelam novos, inesperados, inéditos. (CALVINO, 1993, p. 12).

Outra tese de Calvino (1993 p. 10) é bastante rica para ilustrar a presente reflexão: "Dizem-se clássicos aqueles livros que constituem uma riqueza para quem os tenha lido e amado; mas constituem uma riqueza não menor para quem se reserva a sorte de lê-las pela primeira vez nas melhores condições para apreciá-las." A releitura de uma obra de um clássico instiga sempre a criar algo novo, dada a capacidade de problematizar os temas e as questões. Nesse sentido, podemos trazer presente outra tese de Calvino (1993, p. 10-11), que assinala: "Os clássicos são livros que exercem uma influência particular quando se impõem como inesquecíveis e também quando se ocultam nas dobras da memória, mimetizando-se como inconsciente coletivo ou individual."

Um livro ou um autor clássico sempre provoca saudade que se traduz em reencontro. A cada reencontro, existem novas experiências, sentimentos, emoções, interrogações que emergem nos intervalos históricos. Assim, a provocação para o reencontro é sempre mediada por novas perspectivas. Como afirma Calvino (1993, p.11), "se os livros permaneceram os mesmos (mas também eles mudam, à luz de uma perspectiva histórica diferente), nós com certeza mudamos, e o encontro é um acontecimento totalmente novo." Essa perspectiva aponta para um elemento fundamental que Freire extrai com toda a profundidade da Ideologia Alemã de Marx e Engels (1984): o homem como sujeito histórico e construtor da história. Mais do que isso, pensa na capacidade daqueles excluídos historicamente, tomando consciência das contradições sociais, econômicas e políticas e, ao mesmo tempo, assumindo o papel de sujeito.

Alexander (1999), no artigo "A importância dos clássicos”, evidencia que obras de clássicos foram produzidas a partir de recortes e opções, por vezes, arbitrários. Mesmo com limites, os seus autores foram perspicazes em identificar questões e problemas que ultrapassaram os seus contextos. Preocupar-se com os clássicos, no caso de Freire, implica um Revista Reflexão e Ação, Santa Cruz do Sul, v. 25, n. 2, p. 84-100, Maio./Ago. 2017. http://online.unisc.br/seer/index.php/reflex/index 
movimento de reconhecimento de suas contribuições para pensar as grandes questões atuais. Ler clássicos exige empenho, paciência e capacidade para apreender a profundidade dos questionamentos que fizeram. Nunca olhamos para o passado de forma neutra, por isso, a capacidade interrogativa é um pressuposto para dialogar com os clássicos. Como assevera Calvino (1993, p. 9), a releitura de um clássico é própria de "grandes leitores". Mais do que isso, essa percepção mais profunda não ocorre na juventude, "idade em que o encontro com o mundo e com os clássicos como parte do mundo vale exatamente enquanto primeiro encontro." Esse primeiro encontro, no entanto, é condição para que ocorra o segundo. O encontro inicial com uma obra clássica deve criar condições para adentrar em novos horizontes e respirar novos ares que permitam oxigenar pulmões e cérebros. Num contexto tão resistente ao passado, como bem identificou Benjamin (1994), o desafio de ler um clássico ganha maior significado na busca de contribuições que possam ajudar a compreender mais profundamente os desafios atuais.

\section{QUESTÕES EMERGENTES INTERROGANDO O PASSADO}

Em nosso entendimento, as questões emergentes são as que tornam, em cada contexto, os fenômenos sociais mais complexos. Essa compreensão traz duas importantes consequências: primeira, de que todo contexto é, a seu modo, complexo. Em segundo, a necessidade de compreender, mesmo que hipoteticamente, os problemas emergentes. Nem sempre as configurações dos novos processos são compreensíveis e de fácil caracterização, especialmente enquanto estão em curso. Nesse sentido, podemos dizer que a complexidade de um dado contexto está vinculada às realidades emergentes, mas também implica os referenciais teóricos, epistemológicos e metodológicos. São os referenciais que dão condições para uma problematização mais profunda e adequada aos processos socioeducativos, políticos e culturais. Ao responder algumas críticas de ser pouco ou nada original, Freire replicou: "a originalidade não está no fantástico, mas no novo uso de coisas conhecidas" (FREIRE, 1983, p.122, nota 24). Essa capacidade de problematizar temas e questões, produzindo estranhamentos, é condição para adentrar os problemas de modo mais profundo, a fim de apreender as complexas relações que estabelecem. Num certo sentido, essa reflexão leva a sério a célebre frase de Marx que afirma ser o real resultante de múltiplas relações e determinações. Ao discutir o método da economia política, ele chama a atenção para a necessidade de superar conceitos abstratos, ocos e caóticos e, por outro lado, levar em consideração "uma rica totalidade de determinações e de relações numerosas" (MARX, 1983, Revista Reflexão e Ação, Santa Cruz do Sul, v. 25, n. 2, p. 84-100, Maio./Ago. 2017.

http://online.unisc.br/seer/index.php/reflex/index 
p. 218). Até que ponto essas complexas relações são levadas em consideração quando se estuda um autor clássico ou quando se desenvolvem pesquisas? O diálogo entre a realidade, em suas diversas expressões, com os autores clássicos coloca-se como um desafio para qualquer pesquisador.

No horizonte dessa compreensão, todo contexto é complexo e a complexidade reside, fundamentalmente, naquilo que é emergente, ou seja, naquilo que há de novo em relação aos contextos precedentes. Nesse sentido, podemos trazer presente as contribuições de Raymond Williams, fazendo um esforço para fundamentar uma perspectiva que todo fenômeno social necessita ser compreendido, levando-se em conta uma tríplice dimensão: o dominante (hegemônico), o residual e o emergente. Como essas dimensões são definidas e como se entrecruzam? Em relação ao dominante, pondera Williams (2011, p. 53):

\begin{abstract}
Em qualquer sociedade e em qualquer período específicos há um sistema central de práticas, significados e valores que podemos chamar propriamente de dominante e eficaz (...). De qualquer forma, o que tenho em mente é o sistema central, efetivo e dominante de significados e valores que não são meramente abstratos, mas que são organizados e vividos. É por isso que a hegemonia não pode ser entendida no plano da mera opinião ou manipulação.
\end{abstract}

Por residual, Williams (2011, p. 56) compreende os elementos que são constitutivos das experiências passadas e que persistem no tempo presente. No entanto, esses significados e valores "não podem ser verificados ou não podem ser expressos nos termos da cultura dominante", visto que não mantêm essa posição. Eles são vividos e praticados como resíduos culturais e sociais constituídos em formações sociais anteriores. "Uma cultura residual está geralmente a certa distância da cultura dominante efetiva, mas é preciso reconhecer que, em atividades culturais reais, a cultura residual pode ser incorporada à dominante.”

Para o autor Williams (2011, p. 57), o emergente diz respeito aos "novos significados e valores, novas práticas, novos sentidos e experiências que estão sendo continuamente criados." Por ser emergente, nem sempre apresenta todas as características de processos consolidados. $\mathrm{O}$ emergente precisa ser apreendido em meio às tensões entre o dominante $\mathrm{e} o$ residual, o que só pode ocorrer com análises precisas e temporais entre "o residual incorporado e o residual não incorporado, e entre o emergente incorporado e o emergente não incorporado."

Assim, não existem formas objetivas e simplificadoras sobre como ocorre a incorporação dos valores emergentes, nem a forma como se dá, visto que se trata de processos contraditórios e tensos. Em síntese, podemos afirmar que, em cada contexto específico, 
existem valores que se tornam dominantes, outros que persistem no tempo, mas não alcançam essa posição e, finalmente, os elementos que emergem, ou seja, que surgem em meio às tensões entre os elementos estabelecidos (na condição de dominante ou residual) e os outsiders, para usar a expressão de Norbert Elias e John Scotson (2000). Essa perspectiva sistematizada por Williams tem uma grande potencialidade, porque permite superar os limites das tradições funcionalistas, estruturalistas, culturalistas, entre outras. A sua formação herda importantes elementos da tradição marxista, mas as suas abordagens introduzem elementos das relações culturais, fundamentais para a compreensão de qualquer processo social, especialmente os emergentes.

Voltando ao tópico em questão, podemos afirmar que o passado interroga o presente e esse pressuposto é fundamental na medida em que colocamos essa possibilidade. Não é um ato mecânico, mas depende dos referenciais que adotamos e da compreensão que assumimos. Benjamin acena com essa perspectiva no clássico texto sobre "O conceito de história". A sua crítica ácida aos defensores do progresso e de uma noção linear de tempo tem como pano de fundo uma compreensão do papel relevante do passado para o estudo e a compreensão dos problemas no tempo presente. É a compreensão de que o presente não é um resultado mecânico do desenvolvimento de um princípio metafísico. Essa posição é fundamental para justificar a perspectiva proposta para pensar Freire como um clássico. Essa condição lança um conjunto de desafios para pensá-lo como um autor que foi capaz de refletir em profundidade as questões do seu tempo e, ao mesmo tempo, carrega potencialidades para pensar problemas e desafios atuais, alguns dos quais desenvolveremos a seguir.

\section{DESAFIOS CONTEMPORÂNEOS INTERROGANDO FREIRE}

Existem inúmeros desafios contemporâneos tanto no Brasil quanto no mundo que podem encontrar em Freire elementos para reflexão. Entre esses desafios, podem ser destacados: a educação como ato de conscientização, a condição de sujeito do educando, a democracia como elemento pedagógico fundamental, o diálogo como princípio educativo, o diálogo entre diferentes tradições teóricas e epistêmicas, o ser humano como construtor da história, entre outros.

\subsection{Educar é conscientizar}


Um dos eixos que perpassa a obra de Freire é a noção de conscientização, objeto de reflexão desde os primeiros escritos. Esse primeiro ato é condição fundamental para o desenvolvimento dos demais, entre os quais, o assumir-se como sujeito. No bojo desse compromisso da educação, está um problema extremamente atual que é a dimensão política da educação. Críticas atuais feitas contra Freire, dele ter pensado a educação em sua dimensão política, classificam-no como ideológico. O Movimento "Escola sem Partido"4, contesta veementemente a perspectiva educativa freireana por doutrinar as pessoas. Trata-se, portanto, de um movimento, entre outros, que representa ideais conservadores e preconceituosos que não admitem que outros setores que viveram historicamente a condição de oprimidos tenham consciência das contradições socioculturais, políticas e econômicas e reivindiquem direitos iguais, conforme preceitos constitucionais vigentes. Questões pontuadas por pesquisadores como Jessé Souza (2015; 2016), Renato Ortiz (1994a; 1994b), Florestan Fernandes (1975; 1978), Marilena Chauí (1986; 2004; 2007), entre outros, ajudam a pensar os processos de constituição da sociedade brasileira, destacando as práticas autoritárias, conservadoras e preconceituosas. Essas questões estão na base de um conjunto de outros problemas existentes na atualidade, que se materializam em discriminações e preconceitos sociais e raciais. A elite dominante não admite que setores populares conquistem direitos ou lutem por eles. No máximo, admitem que o Estado dê algum tipo de assistência. Paulo Freire pode ajudar a pensar nessas problemáticas na medida em que pensa o papel do oprimido tomando consciência da sua condição e agindo para superaras relações de opressão.

\subsection{A condição de sujeito do educando}

Um segundo grande desafio que se apresenta para a educação brasileira na atualidade diz respeito à condição de sujeito tanto do aluno quanto do professor em relação à construção do conhecimento visando à intervenção social e política. Assumir-se como sujeito implica ser protagonista da história e do próprio processo educativo. Mesmo havendo diferenças importantes entre a educação formal e a não formal, o problema de fundo continua desafiando a educação brasileira como um todo e tem sido pouco discutido tanto pelas práticas pedagógicas quanto pelas políticas educacionais. Trata-se de pensar o aluno e também o

\footnotetext{
${ }^{4}$ O projeto de lei n. 193/2016, também conhecido como Escola Sem Partido, propõe incluir na LDB (Lei 9.394/1996), o conceito de neutralidade, ideológica e religiosa do Estado. Nesse projeto, defende-se que a educação escolar não pode formar cidadãos politizados e nem questionar os valores familiares. Em linhas gerais, esse projeto postula que a educação escolar não pode formar cidadãos politizados e nem contrariar os valores familiares, cabendo à escola apenas o papel de ensinar "conteúdos científicos".
} 
professor como sujeitos na construção do conhecimento e da história. Como bem observa Charlot (2002), na língua portuguesa, temos um problema que dicotomiza ensinar e aprender. Em geral, essa questão é traduzida pela fórmula: o professor ensina e o aluno aprende. As contribuições de Charlot, nesse sentido, são muito importantes para diagnosticar o problema. Ao tematizar a relação com o saber, ele destaca três questões orientadoras das suas pesquisas: “ $1^{\mathrm{a}}$ ) para um aluno, especialmente de meios populares, qual o sentido de ir à escola? $2^{\mathrm{a}}$ ) para ele, qual o sentido de estudar ou de não estudar na escola? $3^{a}$ ) qual o sentido de aprender, de compreender, quer na escola quer fora da escola" (CHARLOT, 2002, p. 18). Enquanto não houver um assumir da condição de sujeito na construção do conhecimento de parte do aluno e da condição de sujeito que orienta esse processo, de parte do professor, fica difícil pensar em qualquer processo educativo emancipatório. Esse é um dos pontos fundamentais da reflexão freireana.

\subsection{Democracia em sua dimensão pedagógica e na organização do poder}

A concepção de educação nos estudos de Freire tem como finalidade a construção de uma sociedade humanizada, emancipada e democrática. Paulo Freire teve a sua trajetória intelectual e educativa interrompida, no Brasil, pelos governos militares instalados com o golpe de 1964, com todas as consequências, conforme análise feita por Scocuglia (2001), de modo especial os Inquéritos Policiais Militares do período (IPMs), bem como a sua vida de exilado no Chile. Na condição de exilado que estabeleceu contatos com outros países, chegando à África, em 1970, e disseminando a sua produção intelectual em vários lugares no mundo, essa experiência de ruptura abrupta com a liberdade e a democracia, despertou em Freire uma postura radical em defesa de uma educação que contribua na construção de práticas e sujeitos democráticos.

A participação dos sujeitos nos diferentes espaços de poder, tanto os existentes quanto aqueles a serem construídos, coloca-se como condição a partir de uma educação para a democracia, processo que não é natural e nem dado por qualquer pressuposto metafísico. Nesse sentido, todo ato educativo, independente do espaço em que ocorre, deve contribuir para a formação democrática. Essa ideia está articulada à formação política, à conscientização e ao assumir-se como sujeito da história. A democracia não é um mero adorno político, nem um mero ato formal como vem ocorrendo com a democracia liberal representativa, basicamente reduzida ao ato de votar. Ao contrário, ela deve ser expressão das relações de poder que são tensas e contraditórias na medida em que expressam interesses, por vezes Revista Reflexão e Ação, Santa Cruz do Sul, v. 25, n. 2, p. 84-100, Maio./Ago. 2017.

http://online.unisc.br/seer/index.php/reflex/index 
antagônicos, existentes na própria sociedade. Nessa perspectiva, Freire estabelece um diálogo importante com a tradição norte-americana representada por Dewey (1979), bem como em seus desdobramentos no Brasil com Anísio Teixeira (1997). Dewey pensa a democracia na sua forma representativa, ou como forma de governo, mas também como modo de vida associado.

As exigências democráticas colidem frontalmente com qualquer tipo de fundamentalismo ou dogmatismo. Aqui, há um encontro fundamental entre a tradição pragmatista representada por Dewey com o pensamento de Freire e que permite problematizar um conjunto de questões em pauta na sociedade brasileira atual: fanatismos, posturas dogmáticas e fundamentalistas, sejam culturais, religiosas, econômicas, epistêmicas ou políticas. Com a sobreposição de interesses privados em relação aos interesses republicanos, a democracia fica ameaçada. Como explicita Dewey (1979, p. 93), a democracia traz um conjunto de implicações.

Uma vez que a sociedade democrática repudia o princípio da autoridade externa, deve dar-lhe como substitutos a aceitação e o interesse voluntários, e unicamente a educação pode criá-los. Uma democracia é mais que uma forma de governo; é, primacialmente, uma forma de vida associada, de experiência conjunta e mutuamente comunicada.

\subsection{O diálogo como princípio educativo}

Freire é um dos grandes defensores do diálogo concebido como elemento pedagógicoeducativo e também como forma de resolver conflitos. Através do diálogo, a sua pedagogia ganha materialidade e formulações profundas. Recupera o sentido de diálogo do grego: do radical "diá", significando aquilo que se põe em campos distintos, portanto, pressupõe a diferença, e "logos", significando predisposição para estabelecer interlocuções. Assim, o diálogo é a condição para que distintos sujeitos confrontem os seus diferentes pontos de vista, de modo respeitoso. Onde todos pensam da mesma forma, o diálogo deixa de existir, visto que ele pressupõe a diversidade e também a disposição para um confronto positivo.

Qualquer diagnóstico minimamente sério dos desafios contemporâneos não pode desconsiderar a presença de conflitos entre países, no interior das nações, no âmbito das instituições sociais (Estado, escolas, universidades, famílias, entre outras), motivados por razões políticas, éticas, raciais, econômicas, religiosas e epistemológicas. Multiplicam-se as formas de violência decorrentes de pressupostos fundamentalistas e dogmáticos, ao mesmo tempo em que perspectivas epistêmicas apontam para o papel central do diálogo na produção

Revista Reflexão e Ação, Santa Cruz do Sul, v. 25, n. 2, p. 84-100, Maio./Ago. 2017.

http://online.unisc.br/seer/index.php/reflex/index 
do conhecimento, posturas dogmáticas e fundamentalistas proliferam pautadas em pressupostos absolutos que negam qualquer possibilidade da diversidade e do outro. Visões binárias acirram polarizações entre o bem e o mal, o certo e o errado, com graves implicações políticas e sociais. Essas posturas carecem de um princípio básico que é o diálogo, tão defendido por Freire ao longo de suas práticas e reflexões epistêmicas e pedagógicas.

\subsection{A contribuição de diferentes tradições teóricas e epistêmicas}

A discussão teórica de Paulo Freire é altamente complexa por ser constituída por um grande número de mediações que são necessárias para compreender a combinação dos diferentes pressupostos teóricos e epistemológicos. Para contextualizar Freire, é necessário ter um mínimo de compreensão da sua visão, que articula conjuntamente uma postura de latinoamericano e as influências católica, personalista, humanista, marxista, entre outras. A construção de uma proposta pedagógica crítica e emancipatória compreende, respectivamente, a sua luta política em movimentos socioculturais populares, pressupostos utópicos e a defesa da capacidade emancipadora dos oprimidos. Esse quadro de influências apresenta-se como uma síntese difícil de ser compreendida na sua totalidade, sem o auxílio de mediações, visto que são matrizes epistêmicas distintas. Segundo afirmam Oliveira e Dominice (1981, p.136), "somente aqueles que são um pouco de todas essas personagens ao mesmo tempo, ou que tenham passado por diferentes 'fases' e 'influências', podem realmente compreender a intenção de Freire e a totalidade de seu recurso intelectual." Freire não parte de uma tradição ou de um autor para pensar os problemas educacionais, econômicos e sociopolíticos. Ao contrário, a sua experiência junto aos oprimidos é que coloca questões profundas e, desse ponto de partida, ele vai em busca de fundamentação para teorizar. Esse processo de formação é, em Freire, dialético.

Freire combina a influência cristã em sua formação com a tradição da sociologia crítica, bem como com os estudos filosóficos provenientes da tradição hegeliana (dialética) e de Marx, num diálogo constante com a realidade. Freire vai construindo algumas definições conceituais, inserindo-as em seu arcabouço conceitual, inovando tanto teoricamente como com a sua perspectiva política da educação. É isso que ele mesmo reflete quando pontua

Em última análise, devo dizer que tanto minha posição cristã quanto a minha aproximação de Marx, ambas jamais se deram ao nível intelectualista, mas sempre referidas ao concreto. Não fui às classes oprimidas por causa de Marx. Fui a Marx por causa delas. O meu encontro com elas é que me fez encontrar Marx e não o contrário. (FREIRE, 1979, p.74-75). 


\subsection{O oprimido como sujeito da história}

Por fim, um desafio central proposto por Freire em seus escritos, muito importante para pensar a educação brasileira atual, é o papel do sujeito frente ao mundo. Segundo Freire, a educação constitui um processo de humanização continuado e ele ocorre com a abertura do ser humano à complexidade e à responsabilização com o mundo compartilhado. Educar para humanizar implica tomar consciência das contradições que a realidade apresenta. O ser humano transforma-se em sujeito no momento em que toma para si a responsabilidade pelo mundo que compartilha com outros sujeitos. Aqui, cabe a seguinte pergunta: por que tanta resistência de setores conservadores em aceitar que a educação tem um papel fundamental na formação de sujeitos críticos e transformadores da realidade atual?

Assumir-se como sujeito, implica a consciência de perceber que a realidade é resultante da tensão e da contradição entre interesses dos opressores e dos oprimidos e que, na condição de oprimido, a ação no mundo precisa ser crítica e transformadora. A educação é a principal responsável por essa formação crítica. Essa postura coloca em xeque a simplificação de grupos conservadores que desejam consolidar uma educação neutra nas escolas brasileiras. $\mathrm{Na}$ realidade brasileira, o poder econômico e político é desigualmente distribuído. Nesse contexto, uma escola que deixe de problematizar as desigualdades não é neutra, mas conivente com a opressão dos despossuídos.

O conteúdo educativo não pode estar limitado a objetivos tecnicistas que interessem ao mercado e para ser avaliado em concursos de seleção, mas o objetivo é a formação de sujeitos. Na concepção freireana de educação para autonomia e para a liberdade, o conteúdo educativo precisa ser crítico, com potencial de humanização e da consciência dos sujeitos.

\footnotetext{
A realidade social, objetiva, não que existe por acaso, mas como produto da ação dos homens, também não se transforma por acaso. Se os homens são os produtores desta realidade e se esta, na 'inversão da práxis', se volta sobre eles e os condiciona, transformar a realidade opressora é tarefa histórica, é tarefa dos homens. (FREIRE, 2002, p.37).
}

Essa é uma problematização fundamental a ser resgatada para a análise crítica dos conteúdos educativos e pedagógicos presentes na educação brasileira. O conteúdo da educação precisa transcender elementos técnicos e limitados à profissionalização, ampliando os debates sobre o potencial que eles possuem na humanização crítica dos sujeitos. 


\section{CONSIDERAÇÕES FINAIS}

Ao concluir essas reflexões, reafirma-se a tese que Paulo Freire é um clássico da educação, de modo particular, pelas suas contribuições epistêmicas, políticas e pedagógicas. As preocupações que transversalizam a sua obra colocam em pauta um conjunto de desafios que não apenas responderam às interrogações emergentes nos diferentes contextos em que atuou. Elas continuam provocando inquietações em educadores que partilham de uma concepção de educação humanizadora e emancipatória.

As contribuições de Calvino e de Williams no contexto da presente reflexão não tiveram outro propósito que o de trazer alguns pressupostos para destacar ainda mais a obra de Freire, que continua sendo um clássico porque abordou de modo profundo questões políticas, epistêmicas e pedagógicas que ultrapassaram o contexto imediato de suas formulações. Uma das grandes contribuições de Williams está em ressaltar a função provocativa dos desafios emergentes em cada contexto para interrogar os clássicos em busca de respostas adequadas.

Freire é um clássico da educação, não apenas no Brasil. O reconhecimento das suas reflexões vem crescendo em muitos países. Tratá-lo como clássico traz importantes implicações, entre as quais, a de ser tratado como um pensador fecundo, capaz de provocar reflexões propositivas e a sua atualidade está em apontar para possibilidades emancipadoras frente a tantos processos opressivos. Nesse sentido, é fundamental qualificar epistemologicamente os questionamentos em relação à sociedade, às desigualdades sociais e econômicas, à alfabetização, aqui compreendida como capacidade de ler o mundo, às possibilidades de uma educação emancipadora, em que alunos e professores assumam-se na condição de sujeitos da história.

A complexidade dos fenômenos sociais e educativos exige uma crescente abertura para um diálogo com diferentes tradições e pensadores. Isso não implica, como Freire bem demonstra em toda a sua obra, uma postura aberta e não dogmática e fundamentalista. Ao contrário, é fundamental avançar no estabelecimento de um diálogo com outras tradições a partir de problemas atuais.

Vivemos num contexto marcado por profundas contradições sociais, culturais, econômicas e políticas, ao mesmo tempo em que dispomos de muito mais recursos científicos e tecnológicos do que Freire teve a oportunidade de partilhar, experienciamos práticas de desumanização e de opressão crescentes. Em inúmeros espaços sociais e virtuais, posturas homofóbicas, discriminatórias e preconceituosas sobrepõem-se à cidadania e à democracia. A humanização como valor fundamental em Freire pode interrogar essas práticas opressoras.

Revista Reflexão e Ação, Santa Cruz do Sul, v. 25, n. 2, p. 84-100, Maio./Ago. 2017.

http://online.unisc.br/seer/index.php/reflex/index 
Em síntese, tentamos fundamentar no presente texto algumas razões que justificam a importância de ler e problematizar as contribuições de Freire. As problemáticas elencadas como fundamentais são apenas indicadores possíveis que emergem no contexto atual. Certamente, ele ficaria escandalizado ao deparar-se na atualidade com os crescentes discursos e práticas que excluem dos espaços educativos formais questões de gênero e diversidade e, ao mesmo tempo, defendem a neutralidade política do ato educativo. Com Freire, é possível pensar na profundidade do ato educativo, compreendido como um processo político e humanizador. Numa sociedade tão desigual, como é a brasileira, falar em educação neutra ou apolítica é, no mínimo, uma postura hipócrita. Freire reagiria com muita indignação.

\section{REFERÊNCIAS}

ALEXANDER, Jeffrey C. A importância dos clássicos. In: GUIDDENS, A.; TURNER, J. (Orgs.). Teoria social hoje. São Paulo: EdUnesp, 1999. p. 23-89.

BENJAMIN, Walter. Sobre o conceito de história. In: BENJAMIN, Walter. Magia e técnica, arte e política. 7. ed. São Paulo: Brasiliense, 1994. p. 222-232.

CALVINO, Ítalo. Por que ler os clássicos. São Paulo: Companhia das Letras, 1993.

CHARLOT, Bernard. Relação com a escola e o saber nos bairros populares. Revista Perspectiva, v. 20, número especial, p. 17-34, jul./dez. 2002.

CHAUI, Marilena. Conformismo e resistência: aspectos da cultura popular no Brasil. São Paulo: Brasiliense, 1986.

Marilena. Brasil: mito fundador e sociedade autoritária. São Paulo: Fundação Perseu Abramo, 2004.

Marilena. Cultura e democracia: o discurso competente e outras falas. São Paulo: Cortez, 2007.

DEWEY, John. Democracia e educação: introdução à filosofia da educação. 4.ed. São Paulo: Nacional, 1979.

ELIAS, N.; SCOTSON, J. Os estabelecidos e os outsiders. Rio de Janeiro: Zahar, 2000.

FERNANDES, Florestan. A revolução burguesa no Brasil: ensaio de interpretação sociológica. Rio de Janeiro: Zahar, 1975.

Florestan. A integração do negro na sociedade de classes. São Paulo: Ática 1978, (volumes I e II). 
FREIRE, Paulo. Conscientização: teoria e prática da libertação; São Paulo: Cortez \& Moraes, 1979.

Paulo. Pedagogia do Oprimido. 9.ed. Rio de Janeiro: Paz e Terra, 1981.

Paulo. Educação como prática da liberdade. Rio de Janeiro: Paz e Terra, 1983.

. Paulo. Pedagogia da autonomia: saberes necessários à prática educativa. São Paulo: Paz e Terra, 2002.

MARX, Karl. Contribuição crítica da economia política. 2.ed. São Paulo: Martins Fontes, 1983.

MARX, K.; ENGELS, F. A ideologia alemã. São Paulo: Moraes, 1984.

TORRES, Carlos Alberto. Leitura Crítica de Paulo Freire. São Paulo: Edições Loyola, 1981.

OLIVEIRA, R. Darcy de, DOMINICE, Pierre. Pedagogia dos oprimidos, opressão da pedagogia, o debate pedagógico. In. NOVOA, Carlos Alberto Torres. Leitura Crítica de Paulo Freire. São Paulo: Edições Loyola, 1981, p. 63-71.

Pedagogia dos oprimidos, opressão da pedagogia, o debate pedagógico. In:

TORRES, Carlos Alberto (Org.). Leitura Crítica de Paulo Freire. São Paulo: Edições Loyola, 1981. p. 134-138.

ORTIZ, Renato. Cultura brasileira e identidade nacional. São Paulo: Brasiliense, 1994a.

. Renato. A moderna tradição brasileira: cultura brasileira e indústria cultural. São

Paulo: Brasiliense, 1994b.

SCOCUGLIA, Afonso Celso. Educação Popular: do sistema Paulo Freire aos IPMs da ditadura. João Pessoa: EdUFPB, São Paulo: Cortez; Instituto Paulo Freire, 2001.

SOUZA, Jessé. A tolice da inteligência brasileira: como o país se deixa manipular pela elite. São Paulo: LeYa, 2015.

SOUZA, Jessé. A ralé brasileira: quem é e como vive. 2.ed. Belo Horizonte: EdUFMG, 2016.

TEIXEIRA, Anísio. Educação para a democracia: introdução à administração educacional. 2.ed. Rio de Janeiro: EdUFRJ, 1997.

WILLIAMS, Raymond. Cultura e materialismo. São Paulo: EdUnesp, 2011. 